\title{
Viscozyme $L$ aided flavonoid extraction and identification of quercetin from Saururus chinensis (Lour.) Baill
}

\author{
Hu-Zhe Zheng ${ }^{1,2}$ (D) $\cdot$ Sun-Young Kwon ${ }^{2} \cdot$ Shin-Kyo Chung ${ }^{2}$
}

Received: 24 June 2020 / Accepted: 25 July 2020 / Published Online: 30 September 2020

(C) The Korean Society for Applied Biological Chemistry 2020

\begin{abstract}
In order to enhance the extraction efficiency of flavonoid from Saururus chinensis, carbohydrate-hydrolyzing enzyme Viscozyme L aided extraction techniques have been studied. Then flavonoid composition, as well as quercetin, were also identified using UV/Vis, HPLC/MS, and ${ }^{1} \mathrm{H}-\mathrm{NMR}$. The results showed that favorable extraction conditions were Viscozyme L concentration of $0.25 \mathrm{mg} / \mathrm{g}, \mathrm{pH} 4.2$, reaction at $45^{\circ} \mathrm{C}$ for $12 \mathrm{~h}$. Under the favorable extraction condition, total flavonoid yield $(37.9 \mathrm{mg} / \mathrm{g})$ and quercetin yield $(0.86 \mathrm{mg} / \mathrm{g})$ increased by about 2.0 and 9.6 times, respectively, compared to control group. Interestingly, as a significant flavonoid of $S$. chinensis, flavonoid glycones rutin was hydrolyzed to aglycones quercetin by Viscozyme L. These findings provide scientific and theoretical support for the development quercetin-rich products, which was quickly absorbed by the human body than rutin.
\end{abstract}

Keywords Flavonoid $\cdot$ Identify $\cdot$ Quercetin $\cdot$ Saururus chinensis (Lour.) Baill · Viscozyme L

\section{Introduction}

Saururus Chinensis (Lour.) Baill is a perennial herb that mainly grows in eastern Asia, including Korea, China, and Japan [1-2].

Hu-Zhe Zheng $(\bowtie)$

E-mail: huzhezheng@163.com

${ }^{1}$ Department of Health Science, Jiangsu Food \& Pharmaceutical Science College, Huai'an, 223003, China

${ }^{2}$ School of Food Science and Biotechnology, Kyungpook National University, Daegu 41566, Republic of Korea

This is an Open Access article distributed under the terms of the Creative Commons Attribution Non-Commercial License (http://creativecommons. org/licenses/by-nc/3.0/) which permits unrestricted non-commercial use, distribution, and reproduction in any medium, provided the original work is properly cited.
Which has been reported to exert a variety of biological activities such as anti-allergic activity, anti-arteriosclerosis activity and antiinflammatory activity due to the abundant polyphenols, such as flavan-3-ols, hydroxycinnamic acids, dihydrochalcones, and flavonoid [3-5]. Flavonoids are a large family of secondary plant metabolites, which present in plant tissues be covalently linked to polysaccharides via sugar residues esterified to polysaccharides by $\alpha-1,4$ or $\beta-1,4$ linkage [6]. Quercetin, one of the most important flavonoid, which was most frequently found in fruits, vegetables, and other plant foods as conjugates in glycosylated forms as rutin [7-8]. According to a previous study on the metabolism flavonoid, quercetin was quickly absorbed by the human small intestine than rutin [9-10].

In recent years, to improve the extraction efficiency of flavonoids in plants, carbohydrate hydrolases are often introduced to release complex flavonoids from cell walls [11]. For instance, it is used to extract flavonoid aglycone from persimmon peel [12] and unripe apple [13].

In the present study, the carbohydrate-hydrolyzing enzyme, Viscozyme L aided extraction of flavonoids from S. chinensis, was examined. Besides, flavonoid composition, as well as quercetin, were also identified using UV/Vis, HPLC/MS, and ${ }^{1} \mathrm{H}-\mathrm{NMR}$.

\section{Materials and Methods}

\section{Materials and reagent}

S. chinensis (Lour.) Baill pieces were dried and powdered. Viscozyme L was obtained from Novozymes Co. (from Aspergillus aculeatus, 100 fungal $\beta$-glucanase units $/ \mathrm{mL}$, Bagsvaerd, Denmark), the Silica gel $(40 \mu \mathrm{m})$, Octadesylsilane $(50 \mu \mathrm{m})$, rutin, isoquercetrin, quercetrin, and quercetin were obtained from Sigma Co. (St. Louis, MO, USA). The other reagents were obtained from Duksan Co. (Seoul, Korea). HPLC/UVD (SPD-10A, Shimadzu, Co., Kyoto, Japan), Moderate pressure liquid chromatography (MPLC, Yamazen 540, Japan), HPLC/MS (Agilent Technologies, Palo Alto, CA, USA), NMR (Varian Inc., Palo Alto, CA, USA) were used in this study. 


\section{Flavonoid analysis}

The determination of flavonoid content was according to described by Jin et al. [14] and expressed in mg rutin equivalents per gram of sample (mg RE/g). The investigation of flavonoid composition was performed by a modification of the method of Zheng et al. [11].

\section{Viscozyme $L$ aided flavonoid extraction}

To select an appropriate Viscozyme L aided quercetin extraction conditions, enzyme concentration, solution $\mathrm{pH}$, reaction temperature, and time were studied. Briefly, for enzyme concentration, $1 \mathrm{~g}$ of $S$. chinensis powder was added at different concentrations of enzymes from 0.05 to $1 \mathrm{mg} / \mathrm{g}$, with the enzyme hydrolyzed for $12 \mathrm{~h}$ in $45^{\circ} \mathrm{C}$ at $\mathrm{pH} 4.0$. For solution $\mathrm{pH}$, the sample was added with $0.25 \mathrm{mg} / \mathrm{g}$ enzyme and hydrolyzed for $12 \mathrm{~h}$ at $45{ }^{\circ} \mathrm{C}$ at different enzyme hydrolysis buffer $\mathrm{pH}$ ranging from 3.5 to 5.8 , which adjusted with $0.2 \mathrm{~mol} / \mathrm{L} \mathrm{NaOH}$ and $0.2 \mathrm{~mol} / \mathrm{L} \mathrm{KH} 2 \mathrm{PO} 4$. For the preferred reaction temperature, the sample was added with $0.25 \mathrm{mg} / \mathrm{g}$ enzyme and hydrolyzed for $12 \mathrm{~h}, \mathrm{pH} 4.0$ at different temperatures ranging from 25 to $65{ }^{\circ} \mathrm{C}$. For reaction time, sample was added with $0.25 \mathrm{mg} / \mathrm{g}$ enzyme and hydrolyzed at a different time from 6 to $48 \mathrm{~h}$ in $45^{\circ} \mathrm{C}, \mathrm{pH} \mathrm{4.0}$. After the reaction, all the solution was extracted with $95 \%$ ethanol for $12 \mathrm{~h}$ at $80{ }^{\circ} \mathrm{C}$ and used to determine the quercetin, respectively.

\section{Isolation and purification of quercetin}

One hundred grams of dried $S$. chinensis powder with enzyme aided extracted at Viscozyme $\mathrm{L}$ concentration of $0.25 \mathrm{mg} / \mathrm{g}$, reaction temperature $45^{\circ} \mathrm{C}$ for $12 \mathrm{~h}, \mathrm{pH} 4.2$, and the crude solution was extracted with $95 \%$ ethanol for $12 \mathrm{~h}$ in $80^{\circ} \mathrm{C}$. Then, the crude solution was collected for flavonoid analysis. The crude solution was concentrated by rotary evaporator and isolated by partitioning extract first between ethyl acetate and aqueous phase according to its polarity for purification of quercetin. The ethyl acetate portion was further treated chromatographically, alternating between the Silica gel column $(30 \times 300 \mathrm{~mm}$, i.d. $)$ and ODS column $(26 \times 300 \mathrm{~mm}$, i.d.). Then, the column was washed sequentially using the solvent systems and obtained sub-fractions 1-5. After checked with UV/Vis and HPLC, compound 2 was later rotary-evaporated, freeze-dried, and stored at $-15^{\circ} \mathrm{C}$ for structure analysis (Fig. 1).

\section{Instrumental identification}

The HPLC/MS analysis was carried out to identify the molecular weight of the isolated compound. An ODS column (Thermo Hypersil Gold, i.d.; $5 \mu \mathrm{M}, 250 \times 4.6 \mathrm{~mm}$ ), mobile phase solvent $\mathrm{A}$ (acetic acid $/ \mathrm{H}_{2} \mathrm{O}$ ), solvent $\mathrm{B}$ (acetic acid/acetonitrile/ $\mathrm{H}_{2} \mathrm{O}$ ) were adopted. Mass spectra were simultaneously acquired using electrospray ionization in the negative ionization (NI) modes at fragmentation voltages $(80 \mathrm{eV})$ for the mass range of $100-2000 \mathrm{amu}\left(350{ }^{\circ} \mathrm{C}\right.$, $30 \mathrm{psi}) .{ }^{1} \mathrm{H}$ NMR spectra were measured on a Varian model AMX-500 Spectrometer at $500 \mathrm{MHz}$. The isolated compound was

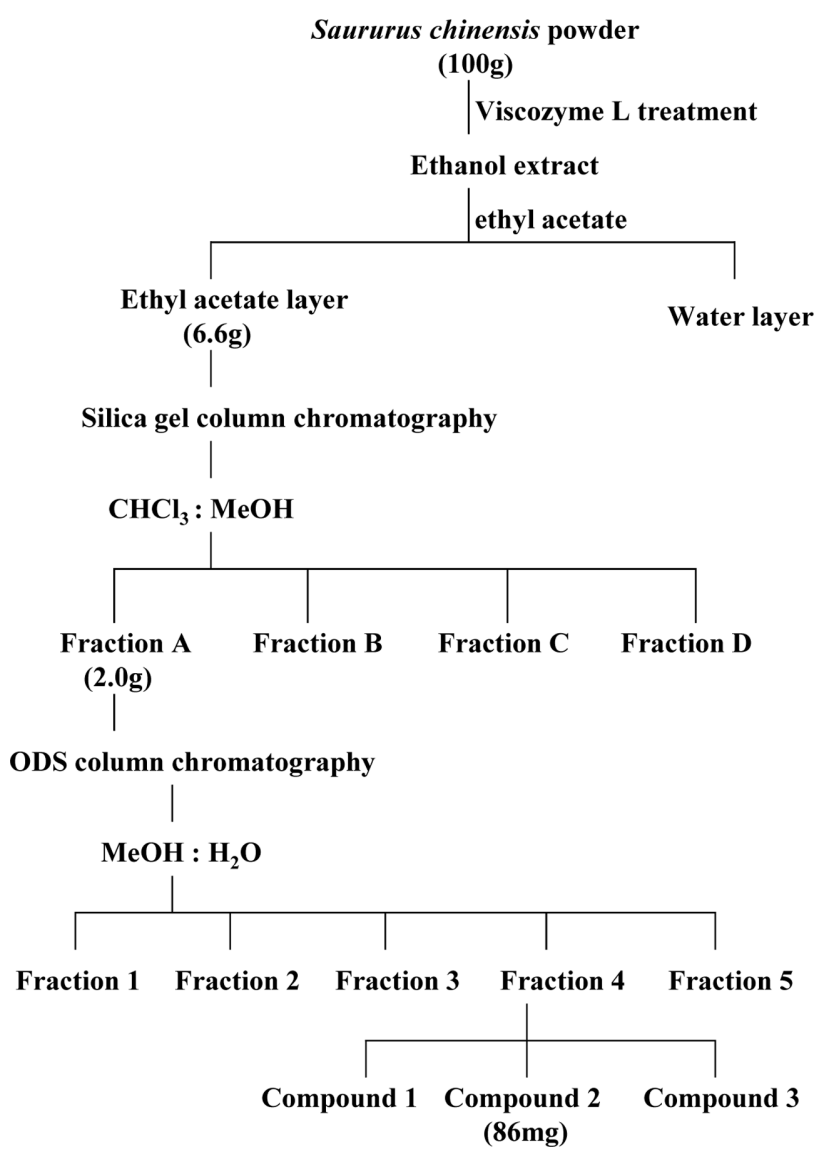

Fig. 1 Extraction and isolation schemes of flavonoid from S. chinensis

soluted in CD3OD, which was previously contained the TMS as an internal standard. Chemical shifts were expressed in ppm relative to TMS, and coupling constants $(\mathrm{J})$ are reported in Hertz (Hz).

\section{Results and Discussion}

\section{Effects of variables on flavonoid extraction}

In general, the efficiency of the enzyme aided extraction of flavonoids from the plant materials was influenced by enzyme concentration, reaction temperature, time, and solution $\mathrm{pH}$, etc. [13]. So, the effects of key variables were investigated for determining the best flavonoid extraction condition from $S$. chinensis. Fig. 2A showed the effects of the Viscozyme L concentration on flavonoid extraction. Flavonoid content was sharply increased at a low concentration of Viscozyme L treatments but maintained invariant at a high concentration of $0.25 \mathrm{mg} / \mathrm{g}$. The reaction solution's $\mathrm{pH}$ affects enzyme activity, so it plays a vital role in cell wall hydrolysis and flavonoid extraction in plants [11]. Figure 2B showed that flavonoid contents sharply increased, peaked at the reaction solution $\mathrm{pH}$ of 4.2 , and then decreased. The effects of the reaction temperature on the flavonoid extraction showed in Fig. 

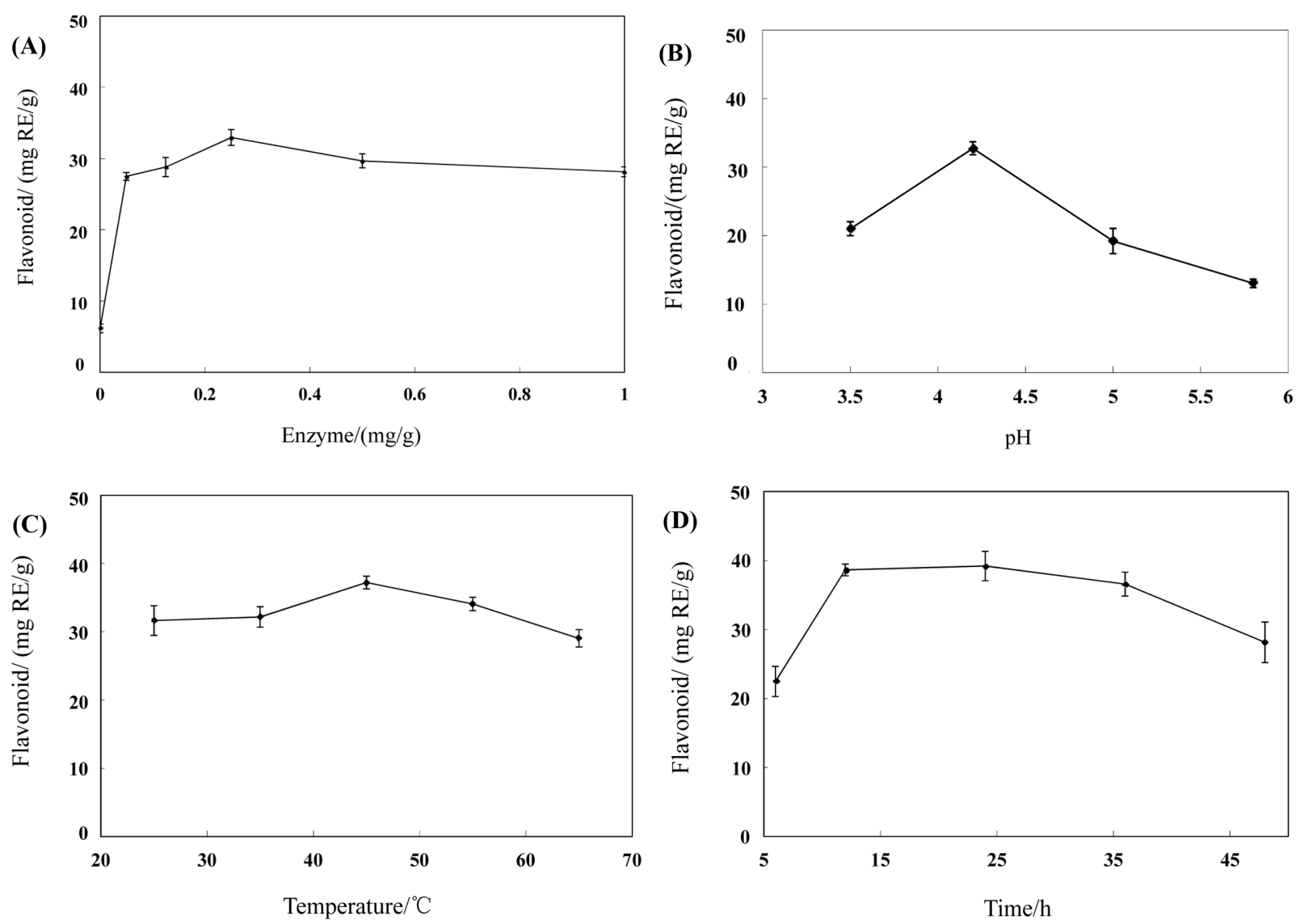

Fig. 2 Effects of (A) the concentration of Viscozyme L; (B) reaction solvent $\mathrm{pH}$; (C) reaction temperature and (D) reaction time on the flavonoid extraction from $S$. chinensis.

2C. Flavonoid contents of enzyme treatments increased smoothly but maintained invariant or gradually decreased over-temperature around $45^{\circ} \mathrm{C}$. These results indicate that within a certain temperature range, with the increase of enzyme reaction temperature, it may be beneficial to increase in the enzyme activity, which could lead to an increase the decomposition activity. In addition, according to the previous research results, an excess decrease or increase of reaction temperature partly inhibited enzyme activity, thereby decreasing flavonoid extraction efficiency. Similar results were reported by Pinelo et al. [15]. They suggested that appropriately temperature may promote possible decomposition of flavonoid from the cell wall, while too high or low temperature had a significantly negative effect on the flavonoid extraction. The effects of the reaction time on flavonoid extraction are shown in Fig. 2D. Flavonoid contents increased sharply along with the reaction time. They reached a peak at $12 \mathrm{~h}$ of reaction and gradually decreased, which may be due to the further decomposition of flavonoids in excess reaction time, destroying the molecular structure of flavonoids. According to experiment results, Viscozyme L concentration of $0.25 \mathrm{mg} / \mathrm{g}, \mathrm{pH} 4.2$, reaction at $45^{\circ} \mathrm{C}$ for $12 \mathrm{~h}$ were selected as the most favorable extraction condition for future purification and identification of flavonoid.

\section{The extraction efficiency of flavonoid with Viscozyme L treatment}

The composition of $S$. chinensis with Viscozyme L aided HPLC analyzed extraction. The four kinds of flavonoids, including rutin, isoquercitrin, queritrin, and quercetin were separated and their contents were detected. As the main flavonoids of $S$. chinensis, rutin and isoquercetin accounted for about $80 \%$ of total flavonoids $[14,16]$. However, the flavonoid composition of the $S$. chinensis in Viscozyme L treatment was significantly different compared to without enzyme treated control, which reflects the reduced rutin content associated with induced quercetin content. Quercetin content induced 9.6 times, whereas the rutin content reduced to 1/9 (Table 1 and Fig. 3). Interestingly, isoquercitrin and queritrin contents showed no significant change between with and without enzyme-treated samples. Rutin (3-O-rhamnosylglucoside) was the derivative compound of quercetin (Fig. 4), which is frequently detected in plants [6]. In this study, an increase of quercetin could be observed by Viscozyme L treatment. Means rutin, a major flavonoid of $S$. chinensis was hydrolyzed to quercetin by carbohydratehydrolyzing enzyme Viscozyme L. The similar results were reported by Zheng et al. [13]. They announced that chlorogenic acid was transformed to caffeic acid from unripe apple during 
Table 1 Extraction efficiency of flavonoid with Viscozyme L treatment from $S$. chinensis

\begin{tabular}{lcc}
\hline \hline \multicolumn{1}{c}{ Flavonoid } & Control & Viscozyme L \\
\hline Total flavonoid Content (mg RE/g) & $18.8 \pm 0.84$ & $37.9 \pm 1.02$ \\
Rutin (mg/g) & $0.95 \pm 0.07$ & $0.10 \pm 0.03$ \\
Isoquercitrin (mg/g) & $0.48 \pm 0.05$ & $0.51 \pm 0.06$ \\
Queritrin (mg/g) & $0.38 \pm 0.08$ & $0.35 \pm 0.05$ \\
Quercetin (mg/g) & $0.09 \pm 0.01$ & $0.86 \pm 0.03$ \\
\hline
\end{tabular}
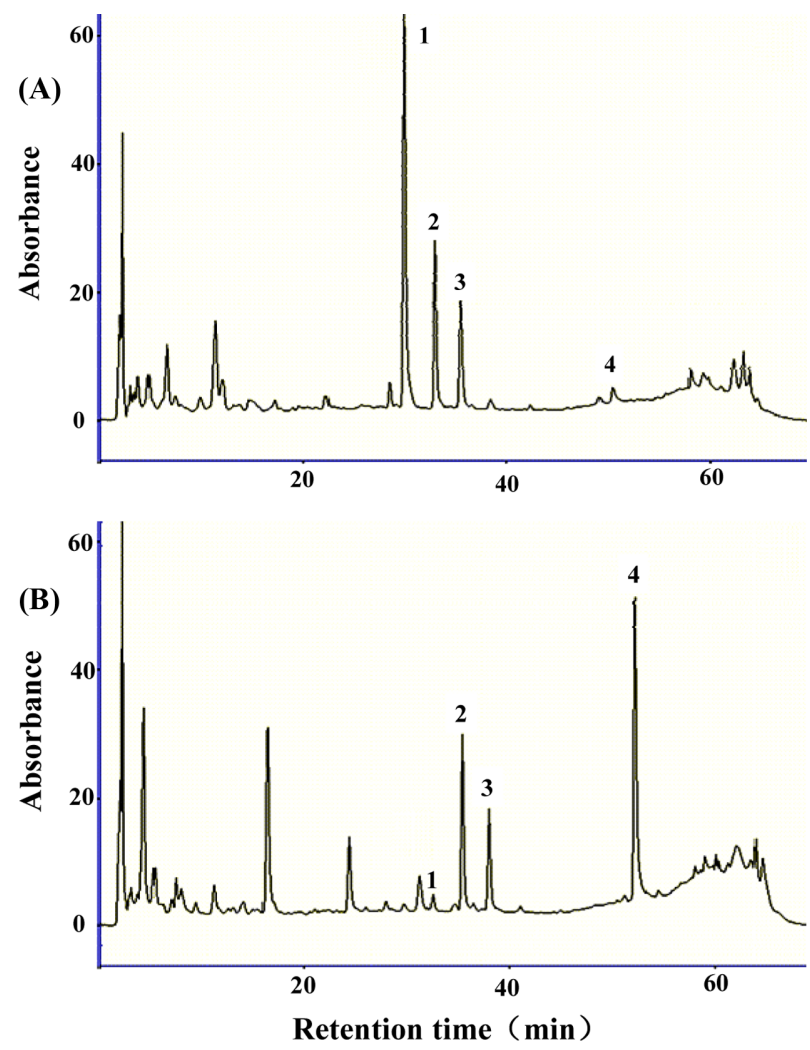

Fig. 3 HPLC chromatograms of $S$. chinensis extracted without (A) and with (B) Viscozyme L aided condition. 1:Rutin, 2: Isoquercitrin, 3: Queritrin, 4: Quercetin

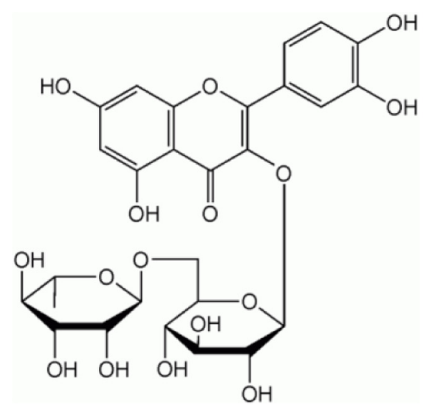

(A)<smiles></smiles>

(B)
Fig. 4 The structure of rutin (A) and quercetin (B)

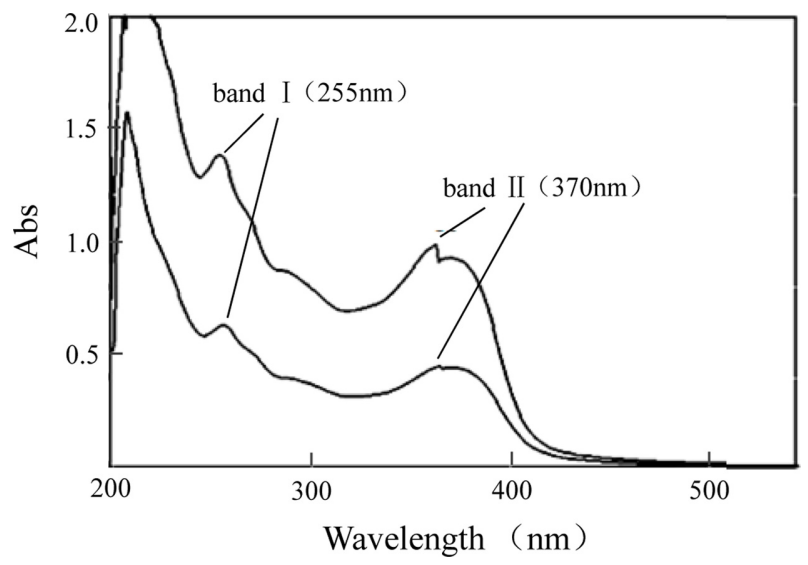

Fig. 5 UV-Vis absorption spectra of quercetin standard (up) and compound 2 (down)

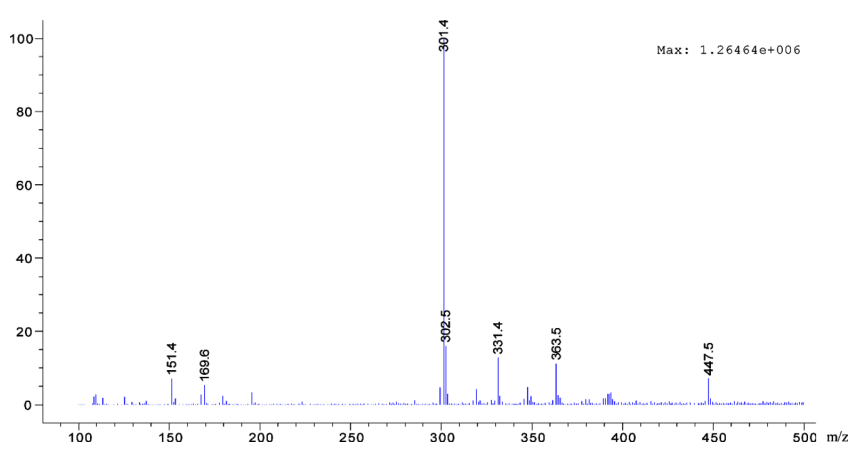

Fig. 6 LC/MS analysis of compound 2 isolated from $S$. chinensis extracted with Viscozyme $\mathrm{L}$ aided condition

carbohydrate-hydrolyzing enzyme extraction. Since then£"caffeic acid has been widely recognized as an important indicator of lignin decomposition during enzymatic hydrolysis. Hence, quercetin also has been suggested as a marker to detect whether cleavage of rutin by carbohydrate-hydrolyzing enzymes has occurred in the plant cell wall.

\section{Isolation and purification of quercetin}

Isolation and purification of quercetin were carried out using MPLC, UV-Visible spectrophotometer. The Silica gel column fraction provides four fractions (Fraction A-D) according to UV absorbance, and then estimated fractions Fr.A was evaporated to dryness under vacuum for further fractionated by an ODS column chromatography using step-gradient elution of $\mathrm{MeOH}: \mathrm{H}_{2} \mathrm{O}$ (0:100-100:0), to yield five sub-fraction (Fraction 1-5), respectively. After removed the solvent by vacuum evaporation, compound 2 (Fig. 5) was identified by HPLC/MS, and ${ }^{1} \mathrm{H}-\mathrm{NMR}$ analysis.

\section{Identification of an isolated compound}

To identify the chemical structure of compound 2, HPLC/MS, and 


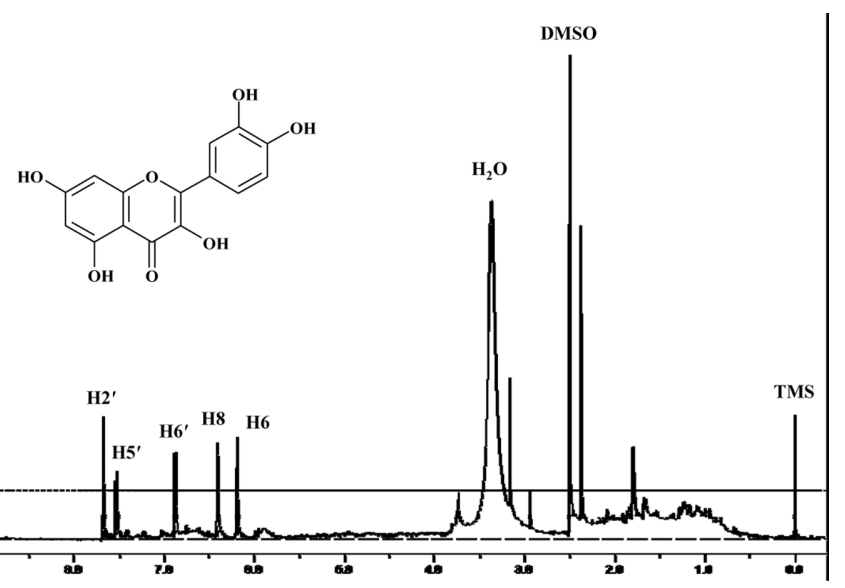

Fig $7{ }^{1} \mathrm{H}-\mathrm{NMR}$ spectrum of compound 2 isolated from $S$. chinensis extracted with Viscozyme $\mathrm{L}$ aided condition

${ }^{1} \mathrm{H}$ NMR analyses were conducted. The MS spectrum mainly showed the ions corresponding to the deprotonated molecule $[\mathrm{M}-\mathrm{H}]^{-}$, which can provide the molecular weight of the compound. The MS spectra presented the ions corresponding to the sugar unit's cleavage or other easily broken units, which can provide the neutral loss information [1]. Compound 2 exhibited a fragment $\mathrm{m} / \mathrm{z} 301$ (Fig. 6). Considering this result and previous research [17-18], the molecular mass of compound 2 could be assumed as quercetin.

${ }^{1} \mathrm{H}-\mathrm{NMR}$ spectrum of compound 2 shows the presence of metacoupled aromatic protons at $\delta 6.187(1 \mathrm{H}, \mathrm{d}, J=2.1 \mathrm{~Hz}, \mathrm{H}-6), \delta$ $6.409(1 \mathrm{H}, \mathrm{d}, J=1.52 \mathrm{~Hz}, \mathrm{H}-8)$, and ortho-coupled ABX type protons at signal $\delta 7.677\left(1 \mathrm{H}, \mathrm{d}, J=2.0 \mathrm{~Hz}, \mathrm{H}-2^{\prime}\right), \delta 7.571(1 \mathrm{H}$, $\left.\mathrm{dd}, J=2.0,8.4 \mathrm{~Hz}, \mathrm{H}-6^{\prime}\right), \delta 6.885\left(1 \mathrm{H}, \mathrm{d}, J=8.4 \mathrm{~Hz}, \mathrm{H}-5^{\prime}\right)$ on the A-ring and B-ring of the skeleton, respectively (Fig. 7). Based on the considering chemical shift of proton and coupling constant, compared with the literature data [19-20], compound 2 was identified as quercetin.

Author's contributions HZZ and SKC conceived and designed the experiments. And both of them performed most of the experiments and wrote the manuscript. SKC revised and edited the manuscript and supervised the work. Both authors have read and approved the final manuscript.

Competing interests The authors declare that they have no competing interests.

\section{References}

1. Wang XY, Huang X, Wang HB (2015) Determination in the content of sauchinone from different medicament portions in Saururus chinensis
(Lour.) Baill. by HPLC. Chinese J Pharmaceutical Anal 35(8): 15051508

2. Li B, Lee YJ, Kim YC (2014) Sauchinone from Saururus chinensis protects vascular inflammation by heme oxygenase-1 induction in human umbilical vein endothelial cells. Phytomedicine 21(2): 101-108

3. An J, Hao DJ, Zhang Q (2016) Natural products for treatment of bone erosive diseases: The effects and mechanisms on inhibiting osteoclastogenesis and bone resorption. Int Immunopharmacol 36: 118-131

4. Basavegowda N, Mishra K, Lee YR (2016) Antioxidant and antityrosinase activities of palladium nanoparticles synthesized using Saururus chinensis. J Clust Sci 27: 733-744

5. Deng YF, Jin F, Li X, Park SJ (2019) Sauchinone suppresses FceImediated mast cell signaling and anaphylaxis through regulation of LKB1/AMPK axis and SHP-1-Syk signaling module. Int Immunopharmacol 74: 11-18

6. Ko MJ, Cheigh CI, Chung MS (2014) Relationship analysis between flavonoids structure and subcritical water extraction (SWE). Food Chem 143: $147-155$

7. Liu XX, Cao GQ, Liu X (2014) Free radical scavenging effects of extracts from Saururus chinensis. Applied Chem Industry 43(5): 877879

8. Kim SJ, Heo DJ, Shin YJ (2012) The effects of subcritical water treatment on antioxidant activity of Saururus chinensis. New Biotechnol 29: 188-189

9. Zhen XP, Fu YY, Xia F (2019) Discovery and activity studies of ATG4B inhibitors from Saururus chinensis L. Nat Prod Res 31: 1252-1257, 1229

10. Jeong HJ, Koo BS, Kang TH (2015) Inhibitory effects of Saururus chinensis and its components on stomach cancer cells. Phytomedicine 22(2): 256-261

11. Zheng HZ, Hwang IW, Kim BK (2014) Phenolics Enrichment Process from Unripe Apples. J Korean Soc Appl Bi 57(4): 457-461

12. Hwang IW, Chung SK, Jeong MC (2013) Optimization of Enzymatic Hydrolysis of Persimmon Peels for Vinegar Fermentation. J Korean Soc Appl Bi 56: 435-440

13. Zheng HZ, Cui CL, Chung SK (2019) Identification of Polyphenols from Unripe Apple with Viscozyme L Extraction. Agri Biotech 8(2): $153-156$

14. Jin JH, Fan JQ, Li JJ (2019) Study on total flavonoids contents and antioxidant activities of Saururus chinensis from different harvesting stages. Ginseng Res 2: 32-34

15. Pinelo M, Arnous A, Meyer AS (2006) Upgrading of grape skins: significance of plant cell-wall structural components and extraction techniques for phenol release. Trends Food Sci Tech 17: 579-590

16. Sun DM, Duan FX, Jiang JY (2019) Simultaneous determination of five flavonoid contents from the different drying process of Saururus chinensis (Lour.) Baill. by UPLC. J Guangdong Pharmaceutical Univer 35(4): 506-510

17. Duan FX, Sun DM, Jiang JY (2019) Study on HPLC-fingerprint of Saururus chinensis (Lour.) Baill. J Guangdong Pharmaceutical Univer 35(2): 221-225

18. Aaron JS, John O, Dan W (2016) Quercetin: A Promising Flavonoid with a Dynamic Ability to Treat Various Diseases, Infections, and Cancers. J Cancer Therapy 16(7): 83-95

19. Anife A, Katarzyna P, Iwona W (2012) ${ }^{1} \mathrm{H},{ }^{13} \mathrm{C}$ MAS NMR and DFT GIAO study of quercetin and its complex with $\mathrm{Al}(\mathrm{III})$ in solid state. J Inorg Biochem 110: 27-35

20. Zuo YM, Xu YL, Zhang ZL (2015) Chemical Constituents from Saururus chinensis. J Chinese Medicinal Materials 38(12): 538-540 